\title{
STUDY OF THE FACTORS AND DEGREE OF ASSOCIATION BETWEEN VARYING POPULATION OF BIRD SPECIES AND THEIR MICROHABITAT
}

\author{
Sombuddha Roy Bhowmick* \\ Department of Biotechnology, St. Xavier's College, India
}

Article History: Received 10 $0^{\text {th }}$ March, 2019; Accepted 22 ${ }^{\text {nd }}$ May, 2019; Published 29 ${ }^{\text {th }}$ May, 2019

\begin{abstract}
Plants and trees support the survival of many species. The aim of this study is to get an elementary idea of the role of habitat, mainly the niche, in the growth and survival of the population of the bird species. Two sampling stations were chosen, one at the Chintamani Kar Bird Sanctuary, Kolkata and the other at the East Kolkata Wetlands. Species of birds common to both these regions were chosen and their number was recorded. The population varied to a great extent at these two habitats. Thus, this study aims to focus on the importance of the relationship between the habitat requirements and niche specification of the bird species. It also gives the idea, that conspicuous species like birds are helpful in the study of ecosystem and effects of the rise of pollution in the ecosystem, can be studied, through monitoring the changes, in the interaction of the species with the environmental factors. The present study was concluded with the fact, that their food habits, nesting spaces, local landscape, vegetation and breeding practices affect their growth and population, even in the regions with similar altitude-longitude-latitude scale, temperature and climatic zone (macrohabitat remaining the same, changes occurring in the microhabitat). Micro factors like-nesting space, breeding habits, feeding practices as well as their body features, play an important role in the interactions. Mathematical analysis has been performed upon sample data to figure out the correlation between the two attributes. Thus, consolidated evidence has been created to support the aim of this study. This study has been conducted at a very elementary level and factors in the variation of population like-interspecific and intraspecific interactions and any kind associations could not be included within the scope of this study. But, future findings including the physico-chemical factors as well as, better metrics would give us a better view of our ecological parameters and environmental health. As birds are conspicuous species, their population or change in population from one microhabitat to another, is one of the easiest ways to spot the changing dynamics of our ecosystem. Their niche, habitat requirement and growth and survival is very specific and thus any change in the parameters would in turn change their numbers, in a definite geographical zone. The study focuses on the habitat specifications and how a particular species of bird, interacts with it. Finally, at the end of the study we have tried to establish a correlation between the habitat specifications of the individual bird species with the niche that is how the species, under study interacts with their habitats on a micro-scale i.e., the microhabitat (a very definitive component in our ecosystem that we often overlook at the superficial level).
\end{abstract}

Keywords: Biomonitoring; Microhabitat; Niche; Population; Habitat; Bird species

\section{INTRODUCTION}

A habitat can be defined as the type of environment, in which a particular organism thrives. A microhabitat can be defined as the small scale physical requirements of particular organism or population. Small microhabitats constitute a habitat which subtly differs in humidity exposure to light, temperature, air movement and many other factors. Thus, microhabitats are specific recognizable features of the environment that act as the proximal cues to elicit a settling response from an individual organism.

So, in this study, we try to find the difference in population of different varieties of birds differing in an area where the temperature, latitude-longitude-altitude factors are quite the same. So we shift our focus to the niche and its interaction with the habitat, the most important factor of a microhabitat. *Corresponding author e-mail: sombuddharoybhowmick100@gmail.com
Niche includes the manner in which a species exploit the subset of environment, for survival and reproduction. Spatial scales range from considering the use of a specific perch or foraging substrates to listing biome within the geographic range of the species. Within two or three habitats in a given area with similar attributes, niche defines the population of the species and its growth and in this study we are going to establish this fact. Many factors underlie habitat selection: these factors do not act equally for all species or even for all populations of a single species. Tiwary (2002) termed them as proximate and ultimate factors-

Proximate Factors- These factors are those that when present in abundance, elicit a settling response to birds to use a certain location. Examples may include song perches, nest sites and the vegetation. 
Ultimate Factors- These factors are considered those which are tied directly to survival and reproduction of individuals and species. The distinction between these two factors is not clearly marked but here, we try to understand the difference in the population of the species of birds in different regions of the city of Kolkata and why the population difference exists.

We consider two different places (habitats), to study the variation and the reason of the variation. An extensive study has been done with regards to two different places in the city of Kolkata, India. One of them is Chintamani Kar Bird Sanctuary and the other one is East Kolkata Wetlands (Rajarhat Area).

These habitats are often more manageable areas of study as they are more condensed than the larger part of the mainland ecosystem. MacArthur and Wilson (1967) in their 'The Theory of Island Biogeography' showed that the species richness in an area could be predicted in terms of factors such as habitat area, where they put focus on the role, the microhabitat plays. This theory is considered one of the fundamentals of ecological theory. The application of this theory, to habitat fragments and variation in the population of species in these fragments, suggest that some micro factors within a macro setup is inevitable to cause this differentiation. Patch Dynamics (Steward and White 1985), a conceptual approach to habitat and ecosystem, emphasizes on the dynamics of heterogeneity within a system (each area of an ecosystem is made up of a mosaic of small 'sub ecosystems'). Diverse patches of habitat created by natural disturbance regimes are considered to be critical for the maintenance of this diversity of the ecology. A habitat patch can be defined as a discrete area with a definite shape, spatial configuration and used by a species for breeding and survival. Mosaics are patterned landscapes within ecology, composed of smaller elements and maybe considered as the smaller unit of variation that is being present (Isaksson et al., 2007).

\section{MATERIALS AND METHODS}

The place of study-Chintamani Kar Bird Sanctuary and East Kolkata Wetlands (Rajarhat Area)

The following Table 1 summarizes the places of study in a very compact manner.

Description of the habitat (region)-

1. Chintamani Kar Bird Sanctuary: Dense bushes coverer the sides of the walking path and densely populated with trees. It is generally humid during the summer. The water body, present near the entrance was fully dried. Enormous tall trees, especially mango trees were observed at frequent intervals. It was interspersed with jackfruit, coconut palm, ficus and other trees. Presence of bamboo plantation also attracted various species of birds. The nests of the birds were observed on top of the canopy and the average height of the trees general to this region was around 35-45 $\mathrm{ft}$ with crown radius varying from plant to plant. The area covering this sanctuary contains a mix of orchards, bamboo trees, water bodies and
Table 1: The place of study - Chintamani Kar Bird Sanctuary and East Kolkata Wetlands (Rajarhat Area).

\begin{tabular}{|c|c|c|}
\hline & $\begin{array}{l}\text { Chintamani Kar } \\
\text { Bird Sanctuary }\end{array}$ & $\begin{array}{c}\text { East Kolkata } \\
\text { Wetlands(Rajarhat } \\
\text { Area) }\end{array}$ \\
\hline Area Covered & 17 acres & 12741 hectares \\
\hline $\begin{array}{l}\text { Average } \\
\text { Temperature } \\
\text { during Day }\end{array}$ & $\begin{array}{c}37^{\circ} \mathrm{C} \text { (Summer) } \\
27^{\circ} \mathrm{C} \text { (Winter) }\end{array}$ & $\begin{array}{c}35^{\circ} \mathrm{C} \text { (Summer) } \\
25^{\circ} \mathrm{C} \text { (Winter) }\end{array}$ \\
\hline $\begin{array}{c}\text { Average } \\
\text { Temperature } \\
\text { during Night }\end{array}$ & $\begin{array}{c}32^{\circ} \mathrm{C} \text { (Summer) } \\
13^{\circ} \mathrm{C} \text { (Winter) }\end{array}$ & $\begin{array}{c}28^{\circ} \mathrm{C} \text { (Summer) } \\
12^{\circ} \mathrm{C} \text { (Winter) }\end{array}$ \\
\hline Humidity & Max 91\% Min 57\% & Max $96 \%$ Min $62 \%$ \\
\hline Rainfall & High (Monsoon) & High (July-August) \\
\hline Wind & $5-10 \mathrm{~km} / \mathrm{hr}$ & $5-14 \mathrm{~km} / \mathrm{hr}$ \\
\hline Latitude & $22^{\circ} 25^{\prime} 45^{\prime \prime} \mathrm{N}$ & $22^{\circ} 25^{\prime}$ to $22^{\circ} 40^{\prime} \mathrm{N}$ \\
\hline Longitude & $88^{\circ} 24^{\prime} 4^{\prime \prime} \mathrm{E}$ & $88^{\circ} 22^{\prime}$ to $88^{\circ} 55^{\prime} \mathrm{E}$ \\
\hline
\end{tabular}

wasteland. The tall and extensive bamboo plantation has attracted a lot of bird species dependent on these plantations. CKBS is the house of many common birds of Kolkata, few rare ones as well as migrants. Birds usually make their nests on these tall tree tops and dense canopies. Even during the day, this place is quite dark, as sun rays cannot penetrate the dense and widespread canopies of these tall trees and a pleasant weather is maintained even, during the scorching heat of the summer.

2. East Kolkata Wetland Area: The area is the home to a large number of coconut trees. Other plantations or vegetations observed include cauliflower, pumpkin and sunflower. Paddy cultivation was also observed at certain localized spots in this zone. Across the wetland, various types of water hyacinth could be seen in plenty. Plants such as Giant arrowhead, Water trumpet, Golden fern, Nutgrass and Water spinach are aquatic in origin and are found in these wetlands in abundance. The height of these aquatic plants was measured to be approximately varying between 3.5 and $11 \mathrm{ft}$ and was relatively closer to the ground than found in CKBS. The East Kolkata Wetlands host the largest sewage fed aquaculture in the world. Coconut and bettle trees were also observed in plenty, though these plants were scattered all over. Salt marshes and salt meadows were spotted which is very common. Water hyacinth has been found to be used in this part of the habitat very efficiently, to create a buffer between land and water to prevent soil erosion.

\section{THEORY AND CALCULATIONS}

Bird census data: The line transects method was followed for bird survey and census data table. Stops were made for every 400 meters for data collection in the dense parts of CKBS and in case of East Kolkata Wetland Area stops were made for every 150 metres and it was recorded for all contacts (species under study), on either side of the track traversed. The distance was kept in check throughout the study period 
and ample measures were taken to prevent double counting of the birds. Best efforts were taken to take photographs and reach a satisfactorily accurate sample number for the data table. The species of birds taken into consideration for this study were, Orange Headed Thrush, Sprangled Drongo, Oriental White Eye, Red Avadavat, Long Tailed Shrike and Tricoloured Munia (Costanza et al., 1997, Ali et al., 1999).

The following Table 2 is the record of the number of species observed at different intervals of time.

The data was recorded very cautiously with utmost accuracy and precision, following every guideline. After that we carefully observed the behaviour of the birds' species very minutely taking pictures to get a closer and clear view of their activities. We waited for hours to notice its activity and traced their nests by thoroughly following their trails of flight. This was a very important factor and the toughest part of this study as this observation and findings would only help us to correlate the microhabitat differentiation and the population of the bird species (Rosenzweig, 1981). These 6 species of birds were observed in both these microhabitats and as birds are conspicuous species, their difference in number and density in these two zones were the basic foundations to do this study, and find out the reasons through a very elementary approach (Table 3 ).
Here, we have classified the sample data, according to two attributes, one according to their origin/habitat and the other one according to the time of observation. The bird count in each specific interval of time was added into one group. The two attributes are tested for their independence, with the help of a simple $\chi^{2}$ test (chi square test) (Ge'nard et al., 2013).

Null hypothesis is that the attributes are independent. Alternative Hypothesis states that the attributes are dependent.

Degrees of freedom (d.f.) $=5$

For 5 d.f., the tabulated value of $\chi^{2}$ at $5 \%$ level is 11.070 and at $1 \%$ level is 15.080 . The observed value of $\chi^{2}$ doesn't exceed any of the tabulated values, so it can be concluded that it is highly insignificant.

We therefore, accept the null hypothesis and conclude that the two attributes are independent and they are not associated (Bibby et al., 2000, William et al.).

The habitat or the place from which sample was collected has no relation or effect on the time interval at which the data was collected and thus, this doesn't affect the aim and objective of the study in any way.

In Table 4, the bird count at each specific interval of time for each species were added and placed under one group. Here, some overlap of the number of bird species might have

Table 2: Record of the number of species observed, at different intervals of time.

\begin{tabular}{|c|c|c|c|c|c|c|c|}
\hline $\begin{array}{c}\text { Serial } \\
\text { number }\end{array}$ & $\begin{array}{l}\text { Name of the } \\
\text { Bird Species }\end{array}$ & $\begin{array}{l}\text { Number of } \\
\text { Individual } \\
\text { Species in } \\
\text { Chintamani } \\
\text { Kar Bird } \\
\text { Sanctuary }\end{array}$ & $\begin{array}{l}\text { Number of } \\
\text { Individual } \\
\text { Species in } \\
\text { Chintamani } \\
\text { Kar Bird } \\
\text { Sanctuary }\end{array}$ & $\begin{array}{l}\text { Number of } \\
\text { Individual } \\
\text { Species in } \\
\text { Chintamani } \\
\text { Kar Bird } \\
\text { Sanctuary }\end{array}$ & \begin{tabular}{|c|} 
Number of \\
individual \\
Species in \\
East Kolkata \\
Wetland \\
Region \\
\end{tabular} & \begin{tabular}{|c|} 
Number of \\
individual \\
Species in \\
East Kolkata \\
Wetland \\
Region
\end{tabular} & $\begin{array}{c}\text { Number of } \\
\text { individual } \\
\text { Species in } \\
\text { East Kolkata } \\
\text { Wetland } \\
\text { Region }\end{array}$ \\
\hline & & $\begin{array}{c}\text { 7:00 AM - 8:00 } \\
\text { AM }\end{array}$ & $\begin{array}{l}\text { 9:00 AM - } \\
\text { 10:00 AM }\end{array}$ & $\begin{array}{l}\text { 11:00AM- } \\
\text { 12:00 PM }\end{array}$ & $\begin{array}{c}\text { 7:00 AM - 8:00 } \\
\text { AM }\end{array}$ & $\begin{array}{c}\text { 9:00 AM-10:00 } \\
\text { AM }\end{array}$ & $\begin{array}{c}\text { 11:00AM- } \\
\text { 12:00PM }\end{array}$ \\
\hline 1 & $\begin{array}{c}\text { Orange Headed } \\
\text { Thrush }\end{array}$ & 7 & 8 & 5 & 3 & 3 & 1 \\
\hline 2 & $\begin{array}{l}\text { Sprangled } \\
\text { Drongo }\end{array}$ & 12 & 8 & 9 & 5 & 6 & 6 \\
\hline 3 & $\begin{array}{c}\text { Oriental White } \\
\text { Eye }\end{array}$ & 5 & 3 & 7 & 2 & 1 & 1 \\
\hline 4 & Red Avadavat & 1 & 3 & 3 & 8 & 9 & 6 \\
\hline 5 & $\begin{array}{l}\text { Long-Tailed } \\
\text { Shrike }\end{array}$ & 5 & 7 & 2 & 10 & 9 & 8 \\
\hline 6 & $\begin{array}{l}\text { Tricoloured } \\
\text { Munia }\end{array}$ & 2 & 2 & 4 & 8 & 9 & 4 \\
\hline
\end{tabular}

Table 3: Observations.

\begin{tabular}{|c|c|c|c|}
\hline & $\mathbf{7} \mathbf{a m} \mathbf{- 8} \mathbf{~ a m}$ & $\mathbf{9} \mathbf{a m}-\mathbf{1 0}$ am & $\mathbf{1 1} \mathbf{a m - 1 2} \mathbf{~ p m}$ \\
\hline Chintamani Kar Bird Sanctuary & 32 & 31 & 30 \\
\hline East Kolkata Wetlands & 36 & 37 & 26 \\
\hline
\end{tabular}

Table 4: The bird count at each specific interval of time for each species.

\begin{tabular}{|c|c|c|c|c|c|c|}
\hline & $\begin{array}{c}\text { Orange } \\
\text { Headed Thrush }\end{array}$ & $\begin{array}{c}\text { Sprangled } \\
\text { Drongo }\end{array}$ & $\begin{array}{c}\text { Oriental White } \\
\text { Eye }\end{array}$ & Red Avadavat & $\begin{array}{c}\text { Long Tailed } \\
\text { Shrike }\end{array}$ & $\begin{array}{c}\text { Tricolored } \\
\text { Munia }\end{array}$ \\
\hline Chintamani kar Bird Sanctuary & 20 & 29 & 15 & 7 & 14 & 8 \\
\hline East Kolkata Wetlands & 7 & 17 & 4 & 23 & 27 & 21 \\
\hline
\end{tabular}


occurred, due to theoretical calculations. But, the main aim of this F distribution would not be significantly hampered, by this step (Boulgouris et al., 2009, Hair et al., 2014).

Null Hypothesis, $\mathrm{H}_{\mathrm{o}}$ states that the population of the bird species obtained from two different habitats, have the same standard deviation value. Alternative Hypothesis, $\mathrm{H}_{\mathrm{a}}$ states that the population standard deviations are not equal.

Since, the variance of the sample II (collected from East Kolkata Wetlands) is greater than that of sample I,

The test statistic is $\mathrm{F}=1.25$

Degrees of freedom (d.f.) $=(1,6)$

The tabulated value of $\mathrm{F}$ at $5 \%$ level is 5.99 (approx).

Since the calculated value of $\mathrm{F}=1.94$ is less than 5.99 , it is not significant, and therefore we can conclude that the two populations, belonging to two different habitats may have the same variance.

It means that, the data collected is proportionately distributed from the average value and as the two habitats may have the same variance, it says that the number of records in the sample or data don't spread out much from the mean value and sticks very close to the average value (Aiken et al., 1981, Mark 2010, Joanne et al., 2011).

From Table 4, we have also performed the ANOVA Test.

Null hypothesis states that the population means may be taken to be equal. Alternative Hypothesis states that all population means are not equal.

Observed value of $\mathrm{F}=0.447$

Degrees of freedom $=(5,6)$

Since, the observed value of $\mathrm{F}$ is smaller than both $1 \%$ and $5 \%$ tabulated value of $\mathrm{F}(4.39$ at $5 \%$ level and 8.47 at $1 \%$ level), corresponding to $(5,6)$, we can hence, conclude that the null hypothesis is valid and so the population means of the bird species in the sample may be taken to be equal.

Population means are equal. So, from ANOVA, we can conclude that the separation of variation due to a group of factors from variation due to other groups is quite the same as their means are equal as per the null hypothesis. This result provides stability to the previous inference and strengthens the sample study (Bolker et al., 2008, Ma et al., 2005, Janssen et al., 1997).

\section{RESULTS}

While inferring the data and the observations, we can sum up with the following reasons.

1. Chintamani Kar Bird Sanctuary: Some of the bird species found more commonly and distinctly in good numbers in this habitat are-

\section{A. Orange Headed Thrush (Geokichla citrina)}

These birds are found in more number in the Chintamani Kar Bird Sanctuary than the East Kolkata Wetlands.
Upon our extensive and detailed observations, the reasons that could be concluded are-

a. Their nest is wide with a groove at a height of around 5 meters in tall trees, preferentially mango and ficus trees. Their microhabitats and niche are mainly found in the upper zones of the trees.

b. As we know that these species is a host of the pied cuckoo Clamator jacobinus, a brood parasite, which lay single egg in their nest. In this case, the young of the host bird very often die as they cannot compete with the cuckoo for food. This might be a reason behind the building of nests, within the shades and thick cover of leaves in the tall and shady plants.

Next, on our list of observation is-

\section{B. Oriental White Eye (Zosterops palpebrosus)}

Some reasons behind their abundance in this niche, over the other one based upon our observations are-

a. Their nests are also found on branches at around the same height as the Orange Headed Thrush.

b. These species are highly arboreal and have been observed to rarely descend to grounds. They prefer to sit on the branches of trees which are at the same height as their nests.

c. They are mainly insectivorous species of birds though; they descend to the ground, for fruits of various kinds and mainly nectars of flowers. Mainly they feed on worms, butterflies and soil-insects. Photographs of these birds preying upon butterflies, while searching for nectar in flowers, have also been captured.

\section{Spangled drongo (Dicrurus bracteatus)}

These species of birds are more in number in CKBS than East Kolkata Wetland Area. Some of the reasons based on their habitat and the specialization of this zone, behind their greater numbers are-

a. The nest was located high on the tree. Although, evidences also showed certain instances, where their nests have been found on bushes and medium-length trees, instead of the greater heights.

b. The Drongo has small and weak feet. So, they are not good walkers. So it is made to rely more on its wings and taking insects (beetles, mantids, grasshoppers) directly from flight. They are usually found in open forests or dense bushes. These birds sit upright while perched, and catch insects while in flight.

2. East Kolkata Wetlands (Rajarhat Area): Some of the bird species extensively found in this region (microhabitat) are-

\section{A. Red Avadavat (Amandava amandava)}

These birds are found more in number in the East Kolkata Wetland Region than the Chintamani Kar Bird Sanctuary.

The habitat and niche of this species suit this place.

During observation, the reasons that could be deduced are- 
a. They feed on insects such as, centipedes and caterpillars. They can actually be termed as "ground level feeders". Their feeding also depends on different types of grass seeds and water plants leaves, which are abundant in this region.

b. The nests of these bird species were found, near to the ground, made of grass and sticks and hay. Some of the left away nests were also found among the dense grasslands of the area distributed in certain areas of the vegetation. Holes made in the ground and covered by leaves and soil-mush have also been found and believed to be their breeding places.

\section{B. Long Tailed Shrike or Rufous Backed Shrike (Lanius schach)}

They are actually migratory birds and found in good numbers in East Kolkata Wetland Area than the Chintamani Kar Bird Sanctuary.

Some of the reasons, behind the occurrence of this species in this particular habitat in good numbers are-

a. Their nests have been found in shrubs, bushes and lower branches of trees. The nests are cup shaped made upon the shrubs and bushes.

b. Long Tailed Shrike prefers to remain at low altitudes. It predates upon beetles, lizards and medium sized insects.

They have an upright "shrike" attitude, perched on bushes from which it feeds upon its prey.

Their time of flight is often short spanned, straight and thus most suited for settling in this niche.

And the last of the species, studied in this habitat was -

\section{Tricoloured Munia (Lonchura malacca)}

The deduced inferences behind their preference of this region as their habitat are -

a. They have been very clearly found to be feeding on water plants or the plants growing in the wetlands.

b. These species are also found to be roosting on the dense, grassy banks of the East Kolkata Wetlands.

c. It is known that these species respond very quickly to rainfall and thus flooded habitats.

So, rainfall in wetlands leads to higher levels of food, that these birds feed on and in turn provides ideal conditions for breeding.

Now, when we correlate the habitats and its specifications, with the habitat requirements of these species of birds, we can distinctly understand about the importance and how a microhabitat affects the population of particular species of birds. Thus, microhabitat plays one of the defining roles in determining the total population as well as the population density of a species in a given geographical area. Here, we state that there is an abundance of population of species which changes gradually along various environmental gradients, but individually, not equally to other populations. In that view of individualistic concept of community (Caswell 2001), individual distribution of species give rise to discrete as well as continuum communities where niches very rarely overlap.

\section{DISCUSSION}

Two green zones in the city of Kolkata were chosen-the CKBS and the East Kolkata Wetland Area. Since birds are highly diverse and conspicuous species of the ecosystem and are sentinel to environmental stresses (Hanski 1999, Liebhold et al., 2002, Collinge 2001, Bellier et al., 2007, Soetaert et al., 2009, Jane et al., 2009, Das), they could be studied with respect to their niche, to get a better understanding of the interaction with the habitat as well as the habitat. 6 Species of birds were chosen, which were common to both the places, but their population varied in those places. So we did this study to find out the reason of the drastic difference. While going through the sample data collections, we found that this difference in number of individual species found here had a direct relationship with their ecological practices and we have tried to bring this fact out here through sheer minute and dedicated observations in the field. Such studies in the urban area like Kolkata, India are not found easily, and changing populations of the species may give us an idea about the changing habitat specifications of the ecosystem. Change in the degree of spatial autocorrelation gives us an idea about the ecological state of the habitat and more specifically, its interacting factors with the biotic system. Spatial autocorrelation is actually the values of samples taken close to each other and are more likely to have similar magnitude than by chance alone. When pairs of values are located at a distance apart, they are more similar and the spatial autocorrelation is said to be positive. When the pair of values is less similar, the spatial autocorrelation is said to be negative. Actually, it is very common for values to be positively auto-correlated at shorter distances and negatively auto-correlated at longer distances. This is commonly called 'Tobler's first law of Geography', (1969) which is given as, "everything is related to everything else, but nearby objects is more related than distant objects". Apart from spatial autocorrelation, there is the concept of induced spatial autocorrelation, which arises from the species response to the spatial structure of external factors, which are themselves spatially auto-correlated. Like most ecological data, our sets of data also show certain degrees of spatial autocorrelation, depending on the scale of interest, i.e., the habitats in the study. Though, we must keep in mind that traditional random population samples, tend to overestimate the true value of the variable or infer significant correlation, where there is one actually. Previously many studies have showed that birds are indicators of pollution in an area and simple, elementary studies like this one would help us to catch the need of the hour at the first blow of the strike. Though, it must be noted that factors like interspecies struggle or intraspecies struggle or any kind of symbiosis could not be considered and this is a major drawback of this study. 


\section{CONCLUSION}

In the present study, we could conclude that habitats, especially niche, define the growth and population of the species of birds. Habitat selection is a very important aspect for the survival of the species. Within a small geographical zone with not very steep variations of temperature and vegetation, the observations and final results make us conclude the fact, that the interaction of the species with the food habit, local landscape, nesting and breeding practices in a defined habitat, influences the niche and ultimately the life patterns and growth of that species. Mechanistic SDM's (Species Distribution Modeling) have been more recently developed. In contrast to correlative models, mechanistic SDM's use physiological information about a species (taken from controlled field) to determine the range of environmental conditions within which the species thrives. Such models derived from data from definitive angles, characterize the fundamental niche. A simple model identifies threshold values, outside of which a species cannot survive. A more complex model consists of several micro-models such as thermal performance curves, survival fecundity as well as population dynamics. Geographically referred data are used as inputs in this model framing just like what has been done in this paper. But, while framing an appropriate model from these data, observations and mathematical calculations, one thing that needs attention, is that these models are used for species distribution predictions, independent of the species known range. Mechanistic SDM's can also define the range of shifting species such as invasive species, which are not at equilibrium. This particular study was done considering the primary aspects and following a very elementary process. So in future, such experiments including physico-chemical factors will prove helpful in defining the changing dynamics of our ecosystem due to pollution and better metrics will lead to better insights to these correlation between the niche and the microhabitat and the natural species.

In some cases, Chintamani Kar Bird Sanctuary has been written as CKBS.

\section{ACKNOWLEDGEMENT}

It is an independent study done by the author. The author would like to thank the authorities at CKBS for providing insights and guidance throughout the tenure of the study. The authorities for the waste management system were also very helpful with their insightful views and data. The author would also like to acknowledge the assistance and guidance of Ms. Nayantara Biswas, currently studying in St. Xavier's College (Autonomous), Kolkata in the collection of data of bird species and helping out with the photographs and identification as well as tracking of the birds. Her knowledge on avian species is one of the most determining factors in the conduct of this study. Her constant inspiration and guidance regarding the flow of the paper and observation and methods for the sample distribution modelling is highly commendable. Author would like to thank her, as without her vision, this paper would not have seen its daylight. The author would also like to thank, Ms. Sayantani Paul of St. Xavier's College, was also instrumental with the sorting of mathematical data.

\section{COMPETING INTERESTS}

The author declares no competing interest, whatsoever.

\section{DATA AVAILABILITY STATEMENT}

All the data presented in this paper are to be allowed to be used by public, without any restrictions.

\section{REFERENCES}

1. Tiwary V.M. 2002. Joy of bird watching $1^{\text {st }}$ Edn. Pp: $1-287$.

2. MacArthur R. H. and Wilson E. O. 1967. The theory of island biogeography.

3. Steward, P. T. A. and White, P. S. 1985. The Ecology of Natural Disturbance and Patch Dynamics. Academic Press.

4. Isaksson C., McLaughlin P., Monaghan P., Andersson S. 2007. Functional Ecol., 21: 1123-1129.

5. Costanza R., d'Arge R., de Groot S., Farber M., Grasso B., Hannon B., Limburg S., O’Neil N. R., Paruelo J., Raskin R. G., Sutton P., van den Belt M. 1997. The value of the world's ecosystem services and natural capital. Nature., 387; 253-260.

6. Ali, S. and SD Ripley, S. D. 1999. Handbook of the birds of India and Pakistan.

7. Rosenzweig, M. L. 1981. A theory of habitat selection. Ecol., 62: 327-335.

8. Ge'nard, M., Lescourret, F. 2013. Combining Niche and Dispersal in a Simple Model (NDM) of Species Distribution. PLoS ONE., 8: e79948.

9. Bibby, C., Jones, M., and Marsden S. 2000. Bird surveys. Expedition Field Techniques.

10. William, M. B. and Leonard A. B. The habitat concept in ornithology. Chapter 2, theory and applications.

11. Boulgouris, N. V., Plataniotis, K. N., Tzanakou, E. M. 2009. Biometrics: Theory, Methods, and Applications. Biometrics., Pp: 1-762.

12. Hair, J. F., Black, W. C., Babin, B. J. and Anderson, R. E. 2014. Multivariate data analysis $\left(7^{\text {th }}\right.$ edn). Harlow: Pearson Education Limited.

13. Aiken, L. S., West, S. G., and Reno, R. R. 1991. Multiple regression: testing and interpreting interactions. Newbury Park: Sage Publications.

14. Mark, V. 2010. Conceptual synthesis in community ecology. Q. Rev. Biol., 85: 183-206.

15. Joanne M. W., Sherwood, Linda, M. S., Cristopher, J. W. 2011. Microbiol Prescott's., Pp: 713-738.

16. Bolker, B. M. 2008. Ecological models and data in R. Princeton University Press., Pp: 6-9.

17. Ma, T. and Wang, S. 2005. Bifurcation theory and applications. World Scientific series on nonlinear science series., 53: 392. 
18. Janssen, A., Gool, E. V., Lingeman R., Jacas, J., van de Klashorst, G. 1997. Metapopulation Dynamics of a Persisting Predator-Prey system. Experimental and Applied Acorology., 21: 415-430.

19. Caswell, H. 2001. Matrix Population Models: Construction, Analysis, and Interpretation. Sinauer.

20. Hanski, I. 1999. Metapopulation Ecology. Oxford University Press.

21. Liebhold, A. M., J. Gurevitch, J. 2002. Integrating the statistical analysis of spatial data in ecology. Ecography.

22. Collinge, S.K. 2001. Spatial ecology and biological conservation: Introduction. Biological Conservation. 100: $1-2$.
23. Bellier, E., Monestiez, P., Durbec, J. P., Candau, J. N. 2007. Identifying spatial relationships at multiple scales: principal coordinates of neighbor matrices (PCNM) and geostatistical approaches. Ecography.

24. Soetaert, K. and Herman P. M. J. 2009. A practical guide to ecological modelling. Springer.

25. Jane, E. and John R. L. 2009. Species distribution models: ecological explanation and prediction across space and time. Annual review of Ecology, Evolution and Systematics., 40: 677-697.

26. Das, N. G. Statistical Methods (Volume I \& II). The McGraw Hill Companies. 